\title{
Mapping geographic clusters of new HIV diagnoses to inform granular-level interventions for HIV epidemic control in western Kenya
}

Hellen Muttai ${ }^{1 *}$ D, Bernard Guyah², Thomas Achia ${ }^{1}$, Paul Musingila ${ }^{1}$, Jesse Nakhumwa ${ }^{3}$, Rose Oyoo ${ }^{3}$, Wilfrida Olweny ${ }^{3}$, Redempter Odeny ${ }^{3}$, Spala Ohaga ${ }^{3}$, Kawango Agot ${ }^{3}$, Kennedy Oruenjo ${ }^{4}$, Bob Awino ${ }^{4}$, Rachael H. Joseph ${ }^{1}$, Fredrick Miruka ${ }^{1}$ and Emily Zielinski-Gutierrez ${ }^{5}$

\begin{abstract}
Background: As countries make progress towards HIV epidemic control, there is increasing need to identify finer geographic areas to target HIV interventions. We mapped geographic clusters of new HIV diagnoses, and described factors associated with HIV-positive diagnosis, in order to inform targeting of HIV interventions to finer geographic areas and sub-populations.

Methods: We analyzed data for clients aged $\geq 15$ years who received home-based HIV testing as part of a routine public health program between May 2016 and July 2017 in Siaya County, western Kenya. Geospatial analysis using Kulldorff's spatial scan statistic was used to detect geographic clusters (radius $\leq 5$ kilometers) of new HIV diagnoses. Factors associated with new HIV diagnosis were assessed in a spatially-integrated Bayesian hierarchical model.
\end{abstract}

Results: Of 268,153 clients with HIV test results, 2906 (1.1\%) were diagnosed HIV-positive. We found spatial variation in the distribution of new HIV diagnoses, and identified nine clusters in which the number of new HIV diagnoses was significantly (1.56 to 2.64 times) higher than expected. Sub-populations with significantly higher HIV-positive yield identified in the multivariable spatially-integrated Bayesian model included: clients aged 20-24 years [adjusted relative risk (aRR) 3.45, 95\% Bayesian Credible Intervals (Cl) 2.85-4.20], 25-35 years (aRR 4.76, 95\% Cl 3.92-5.81) and $>35$ years (aRR 2.44, 95\% Cl 1.99-3.00); those in polygamous marriage (aRR 1.84, 95\% Cl 1.55-2.16), or separated/divorced (aRR 3.36, 95\% Cl 2.72-4.08); and clients who reported having never been tested for HIV (aRR $2.35,95 \% \mathrm{Cl} 2.02-2.72$ ), or having been tested $>12$ months ago (aRR 1.53, 95\% Cl 1.41-1.66).

Conclusion: Our study used routine public health program data to identify granular geographic clusters of higher new HIV diagnoses, and sub-populations with higher HIV-positive yield in the setting of a generalized HIV epidemic. In order to target HIV testing and prevention interventions to finer granular geographic areas for maximal epidemiologic impact, integrating geospatial analysis into routine public health programs can be useful.

Keywords: Geospatial analysis, Mapping geographic clusters, New HIV diagnoses, Kenya

\footnotetext{
* Correspondence: hoz1@cdc.gov

'Division of Global HIV \& TB, United States Centers for Disease Control and Prevention, 00621 Nairobi, Kenya

Full list of author information is available at the end of the article
}

(c) The Author(s). 2021 Open Access This article is licensed under a Creative Commons Attribution 4.0 International License, which permits use, sharing, adaptation, distribution and reproduction in any medium or format, as long as you give appropriate credit to the original author(s) and the source, provide a link to the Creative Commons licence, and indicate if changes were made. The images or other third party material in this article are included in the article's Creative Commons. licence, unless indicated otherwise in a credit line to the material. If material is not included in the article's Creative Commons licence and your intended use is not permitted by statutory regulation or exceeds the permitted use, you will need to obtain permission directly from the copyright holder. To view a copy of this licence, visit http://creativecommons.org/licenses/by/4.0/. The Creative Commons Public Domain Dedication waiver (http://creativecommons.org/publicdomain/zero/1.0/) applies to the data made available in this article, unless otherwise stated in a credit line to the data. 


\section{Background}

In 2017, the eastern and southern Africa region had an estimated 800,000 new HIV infections, accounting for $44 \%$ of all new infections worldwide [1]. Reducing new HIV infections is essential for HIV epidemic control [2]. Interventions to prevent transmission of HIV include biomedical (e.g. antiretroviral drug use, medical male circumcision, condom use), behavioral (reducing risky behaviors) and structural (policy formulation and guidelines). Initiation of antiretroviral therapy (ART) at, or soon after, HIV diagnosis, and sustained viral suppression, substantially reduces HIV transmission [3, 4] and HIV-related morbidity and mortality [5]. In 2014, the Joint United Nations Programme on HIV/AIDS (UNAIDS) set ambitious global targets towards achieving HIV epidemic control, recommending programs aim for $90 \%$ of people living with HIV (PLHIV) to know their HIV status, $90 \%$ of people with diagnosed HIV infection to receive sustained ART, and $90 \%$ of people receiving ART to achieve viral suppression [6].

In 2017, Kenya had an estimated HIV prevalence of $4.8 \%$ among individuals aged 15-49 years, and approximately 52,800 new HIV infections. Nationally, with 1.12 million of the estimated 1.5 million PLHIV accessing ART, the country had achieved a population ART coverage of $75 \%$ [7]. Of Kenya's 47 counties, Siaya had the highest HIV prevalence of $21 \%$, with an estimated 123,000 PLHIV, and 4000 new HIV infections [7]. As of September 2017, the county had a population ART coverage of $71 \%$ [7]. In order to accelerate progress towards HIV epidemic control, programs in Siaya intensified implementation of multiple county-wide HIV prevention interventions and testing approaches, including community home-based HIV testing.

In many countries with generalized HIV epidemics, interventions and resource allocation are planned and targeted to large geographic units (primarily county-level in Kenya). As more PLHIV access HIV services, interventions need to reach a diminishing number of people. Strategies to effectively target the delivery of HIV services, including HIV testing, to finer geographic units and sub-populations, are therefore needed, to improve program efficiency.

Geospatial analysis and mapping have been used to demonstrate geospatial clustering (i.e. "micro-epidemics") of HIV infection around geographic, social or behavioral risk factors [8-11]; describe geographic clustering of incident HIV infections [12]; demonstrate within-country variability in the decline of HIV prevalence [13]; describe geographic variability in prevention of mother to child transmission program achievements [14] and variability in HIV testing access [15]; and to guide targeted implementation of HIV testing interventions [16, 17]. Furthermore, multiple studies have described ways to prioritize HIV interventions to specific geographic areas, including areas with higher HIV prevalence $[11,18]$, higher HIV incidence $[18,19]$, and focused prioritization based on local epidemiologic context [20]. Despite the potential utility of geospatial analysis of routine HIV testing program data to map finer geographic clusters of higher new HIV diagnoses in order to inform targeting of HIV testing and prevention interventions, limited studies have been conducted on this. One study done in Kenya used 2015/2016 facilitylevel HIV testing data to describe the spatial distribution of newly diagnosed HIV-positive persons across counties with differing HIV burden [21].

This study uses data from home-based HIV testing conducted as part of a routine public health program in Siaya County, western Kenya. We use geospatial analysis to assess and map granular geographic clusters of new HIV diagnoses, and a spatially-integrated Bayesian hierarchical model to describe factors associated with new HIV diagnoses in order to inform targeting of HIV interventions to finer geographic areas and sub-populations.

\section{Methods}

Study area, design and setting

This study uses data from home-based HIV testing offered as part of a routine public health program in Siaya County. Home-based testing was supported by the United States President's Emergency Plan for AIDS Relief (PEPFAR) through the United States Centers for Disease Control and Prevention (CDC), under the Impact Research and Development Organization cooperative agreement.

Siaya County borders Lake Victoria in western Kenya. The population is predominantly rural, and includes fishing communities living along the lake's beaches. Administratively, the county consists of six sub-counties, which are subdivided into 30 wards, and further into 179 sub-locations, and 2285 villages. In 2016 and 2017 intensified routine HIV testing was implemented in Siaya County, and included biannual testing offered to fishing communities living along the beaches, and home-based testing offered to inland residents of the county.

For home-based HIV testing, all households in the inland geographic areas were visited to enumerate occupants and assess their eligibility for HIV testing. Household occupants were enumerated if they would be resident in the household for one or more months following enumeration. Clients aged $\geq 15$ years were eligible for HIV testing if they reported having never been tested for HIV; reported a negative HIV test done more than 3 months ago; had signs, symptoms or a diagnosis of tuberculosis, or a sexually transmitted infection; or reported a recent (within 3 months) HIV exposure such as unprotected sex with a partner of unknown or positive 
HIV status. Children aged 14 years and below were eligible for testing if their biological mother was known to be HIV infected or deceased. Within 1 month of enumeration, trained lay counselors offered pre-test counseling, HIV testing and post-test counseling to those eligible. Counselors made up to three follow-up visits to offer testing to those not found at home. HIV testing was offered according to the 2015 Kenya HIV testing guidelines [22] using Determine ${ }^{\text {TM }}$ [23] and First Response $^{\circ}$ [24] rapid point of care kits. ${ }^{1}$ An individual was considered HIV-negative (uninfected) if the Determine test result was negative (considered a conclusive negative result), HIV-positive (infected) if both the Determine and First Response serial tests results were positive (considered a conclusive positive result), and inconclusive if the Determine test was positive and First Response test was negative. Clients with inconclusive HIV test results were referred to a health facility for follow-up testing according to Kenya Ministry of Health guidelines.

We retrospectively analyzed data for clients aged $\geq 15$ years who received routine home-based HIV testing in Siaya County from May 2016 to July 2017. Home-based testing data for children aged $<15$ years, and data collected as part of biannual HIV testing of fishing communities were excluded from the analysis. Data were spatially analyzed at sub-location level; sub-locations in which all, or more than half of households were enumerated, were included in the analysis. Out of the 179 sublocations in the county, data from 161 sub-locations met criteria for inclusion (156 sub-locations in which all households were enumerated, and 5 in which $\geq 50 \%$ of households were enumerated).

\section{Data management}

Routine home-based HIV testing data collected included sociodemographic characteristics: age, sex, marital status and relationship to household head; sub-county, ward, sub-location and village of residence; and HIV test eligibility criteria and test results. Data collected were manually recorded on standardized enumeration forms and Ministry of Health HIV testing registers by lay counselors. At a central (office) location, data clerks reviewed the data for completeness and accuracy, and entered it into a secure password-protected Microsoft Access database.

For this study, routinely collected data were stripped all identifiers (names and unique patient numbers) and each record assigned a new study-specific identification number. The analytic dataset was saved in a secure password-protected database.

${ }^{1}$ From the manufacturer's package insert, Determine ${ }^{\text {Thx }}$ has a sensitivity of $100 \%$ and specificity of $99.8 \%$; while First Response ${ }^{\circ}$ has a sensitivity of $100 \%$ and specificity of $99.5 \%$.

\section{Data analysis}

Frequencies, proportions, medians and interquartile ranges were calculated to summarize the data. The proportion of new HIV-positive clients (new HIV-positive yield) was defined as the total number of clients newly identified HIV-positive among those with a conclusive test result. The proportion of total HIV-positive clients was calculated as the sum of new HIV-positive and previously-identified HIV-infected clients among those assessed for HIV test eligibility.

\section{Spatial data analysis}

For spatial analysis, client data were aggregated to the sub-location where they were tested for HIV, and sublocation-level geographic units used for analysis and mapping. Village-level analysis was not possible owing to small numbers and lack of household-level point coordinates.

\section{a) Global Moran's I statistic}

The Global Moran's I statistic was computed using GeoDa software tool version 1.12.1.131 $[25,26]$ in order to assess the presence of spatial autocorrelation of new HIV diagnoses at sub-location level. A significant positive autocorrelation indicates the existence of either high-value or low-value clustering, while a negative autocorrelation indicates a tendency toward the juxtaposition of high values next to low values.

\section{b) Kulldorff's spatial scan statistic}

The Kulldorff's spatial scan statistic [27] was implemented using SaTScan ${ }^{\text {тu }}$ version 9.6 [28] to detect spatial clusters of new HIV diagnoses. Since the proportion of clients newly diagnosed HIV-positive was low, a discrete Poisson probability model was used for scanning. SaTS$\operatorname{can}^{\mathrm{m}}$ software cyclically scans a window across space, calculating the number of observed and expected cases inside the window at each location, and adjusting for spatial inhomogeneity of the background population. The window with the maximum likelihood estimate is considered to be the most likely cluster, rejecting the null hypothesis of no clusters at $p$ value $<0.05$. For our study, the Kulldorff spatial cluster detection looped over all of the 161 sub-locations included in the analysis. We used a maximum spatial cluster size radius of five kilometers $(\mathrm{km})$ in order to inform HIV program implementation meaningfully at a granular sub-location level. Because Siaya County has a generalized epidemic, and it was not possible to segregate the population proportion at higher risk, we assumed $50 \%$ of the total population were at risk of HIV-infection (excluding PLHIV with previously known HIV status) [29]. The maximum number of standard Monte Carlo replications was set to 999 . Significant clusters were reported together with 
corresponding radii, number of observed and expected cases, relative risk, likelihood ratio and $p$-values. Clusters with a relative risk of $>1.0$ at $p$ value $<0.05$ were considered significant clusters of higher new HIV diagnoses; while those with a relative risk of $<1.0$ at $p$ value $<0.05$ were considered significant clusters of lower new HIV diagnoses. A standard Geographical Information System (GIS) program, Quantum GIS version 3.6 [30], was used to map clusters and layer them over ecological features.

\section{c) Mapping of HIV testing uptake}

To describe patterns of HIV testing uptake, quantiles of testing uptake were mapped and overlaid on sublocation clusters of new HIV diagnoses.

\section{d) Bayesian hierarchical spatial model}

We used a Bayesian hierarchical spatial model to assess the relationship between new HIV diagnosis and covariates while accounting for spatial autocorrelation in the data. A Bayesian estimation based on an Integrated Nested Laplace approximation (INLA) was computed using R-INLA package [31]. In a Bayesian framework random effects are unknown quantities assigned to prior distributions that reflect prior knowledge on the structure of the effects, while enabling accounting for heterogeneity across spatial units. We applied a Bayesian approach to client-level and spatial parameters, separately and jointly.

The outcome in our analysis was new HIV-positive diagnosis. The covariates: age, sex, marital status, time since last HIV test and sub-location proportion of total HIV-positive clients, were included in the Bayesian spatial model.

We let $Y_{i j k l m}$ denote the number of new HIV-positive individuals diagnosed among the $n_{i j k l m}$ tested for HIV in the $i$-th sub-location for the $j$-th age category, $k$-th sex, $l$-th marital status and $m$-th time since last HIV test. We assumed that $Y_{i j k l m}$ is a Poisson random variable with mean $E_{i j k l m} \theta_{i j k l m}$. That is, $Y_{i j k l m} \sim \operatorname{Poisson}\left(E_{i j k l m} \theta_{i j k l m}\right)$, where $E_{i j k l m}$ denotes the expected number of cases and $\theta_{i j k l m}$ is the "true" but unknown relative risk in the $i$-th sub-location for the $j$-th age category, $k$-th sex, $l$-th marital status and $m$-th time since last HIV test.

We used the Besag-York-Mollié (BYM) model [32, 33] of the form:

$$
\log \left(\pi_{i j k l m}\right)=\beta_{0}+\boldsymbol{X}_{i j k l m} \boldsymbol{\beta}+u_{i}+v_{i}
$$

where $\beta_{0}$ is the intercept that represents the overall logodds of a new HIV-positive diagnosis; $\boldsymbol{\beta}$ is a vector of parameters associated with the vector of covariate $\boldsymbol{X}_{i j k l m}$; $u_{i}$ is a spatial structured component modeled with a conditional autoregressive (CAR) distribution $u_{i} \mid \boldsymbol{u}_{-i}$ $\sim N\left(\bar{u}_{\delta_{i}}, \frac{\sigma_{u}^{2}}{n_{\delta_{i}}}\right)$, where $\bar{u}_{\delta_{i}}=n_{\delta_{i}}{ }^{-1} \sum_{j \in \delta_{i}} u_{j}, \delta_{i}$ and $n_{\delta_{i}}$ repre- sent the set of neighbors and the number of neighbors of sublocation $i$ respectively; and $v_{i}$ is an unstructured spatial effect defined as $v_{i} \sim N\left(0, \sigma_{v}^{2}\right)$. The Besag York Mollié Poisson model [32] includes an ordinary randomeffects component for non-spatial heterogeneity.

The posterior distributions of the parameters in the Bayesian spatial model were estimated via an Integrated Nested Laplace Approximation (INLA) approach in $\mathrm{R}$ statistical package, borrowing strength across sublocations to produce smoothed sublocation level estimates even where the data were sparse. Full list of the latent models, likelihoods and prior assumptions can be found in the R-INLA website at http://www.r-inla.org/ [31].

Unadjusted relative risk (uRR) and 95\% Bayesian credible intervals (CIs) were computed to describe univariate associations. A multivariable Bayesian spatial Poisson model was used to assess the performance of four non-spatial and spatial models: fixed effects only, fixed effects in a spatially unstructured model, fixed effects in a spatially structured model, and fixed effects in a convolution unstructured and structured spatial random effects model. The convolution model, additionally allows for both spatially structured and unstructured heterogeneity in one model [34]. We reported measures of adjusted relative risk (aRR), 95\% Bayesian CIs, precision of the spatially unstructured and structured random effect model, and the deviance information criterion (smaller values indicating better model performance).

Random effects maps of residual variability of new HIV diagnoses, not accounted for by the explanatory variables, were generated from the convolution Bayesian Poisson model, and mapped using ggplot2 $\mathrm{R}$ package [35]. These included unstructured random effects maps, showing variability when spatial autocorrelation was not taken into account, and structured random effects maps, when spatial autocorrelation was accounted for.

The Bayesian approach allows the posterior probability of any area's relative risk exceeding a threshold to be calculated. A threshold of 1.25 was used in our analysis; noting that it would have been possible to use a different threshold $>1.0$ (denoting an area's higher relative risk). This probability is an important tool for the assessment of unusual elevated risk of disease [36, 37]. From the posterior marginals of the relative risk, $\hat{\theta}_{i j k l m}=\exp \left(\hat{\beta}_{0}\right.$ $\left.+\boldsymbol{X}_{i j k l m} \hat{\boldsymbol{\beta}}+u_{i}+v_{i}\right)$, the exceedance probability was calculated and is defined as $\operatorname{Pr}\left(\theta>\theta^{*}\right)=\sum_{g=1}^{G} I\left(\theta^{(g)}>\theta^{*}\right.$ ), where $G$ is the sampler sample size. Wherever this probability is high there is evidence that the excess risk is not only high, but significantly high. 


\section{Results}

From the 161 Siaya administrative sub-locations included in the analysis, 365,798 clients aged $\geq 15$ years from 136,607 households were enumerated for homebased HIV testing (Fig. 1). Among those enumerated, 136,607 (37\%) were household-heads, 80,161 (22\%) were spouses, 110,255 (30\%) were children aged $\geq 15$ years, and 38,775 (11\%) were other relatives/non-relatives (Table 1). Overall, those enumerated had a median age of 30 years (interquartile range 20-47 years), and 203,170 (56\%) were women.

Of the total clients enumerated, 355,277 (97\%) were assessed for HIV testing eligibility, and 312,223 (88\%) were eligible for testing (Fig. 1, Table 1). Among those eligible, 268,543 (86\%) were tested for HIV, and 2906 (1.1\%) of 268,153 clients with conclusive HIV test results were diagnosed HIV-positive. The new HIV positive yield by different characteristics is shown in Table 1 and supplemental Fig. S1. The reasons for not testing among eligible clients are shown in Fig. 1.

The 161 sub-locations had a median HIV testing uptake among eligible clients of $87 \%$ (interquartile range $82-91 \%$ ), a median new HIV-positive yield of $1.1 \%$ (interquartile range $0.8-1.5 \%$ ), and a median proportion of total HIV-positive clients of 9.1\% (interquartile range 7.6-10.4\%), (Table 1). Maps showing the sub-location distribution of new HIV-positive yield, proportion of total HIV-positive clients, and the distribution of different client characteristics are shown in supplemental Fig. S2.

\section{Spatial clusters of new HIV diagnoses}

Sub-location level Moran's I analysis yielded an index of 0.2925 ( $p$ value $<0.001)$, indicating the presence of

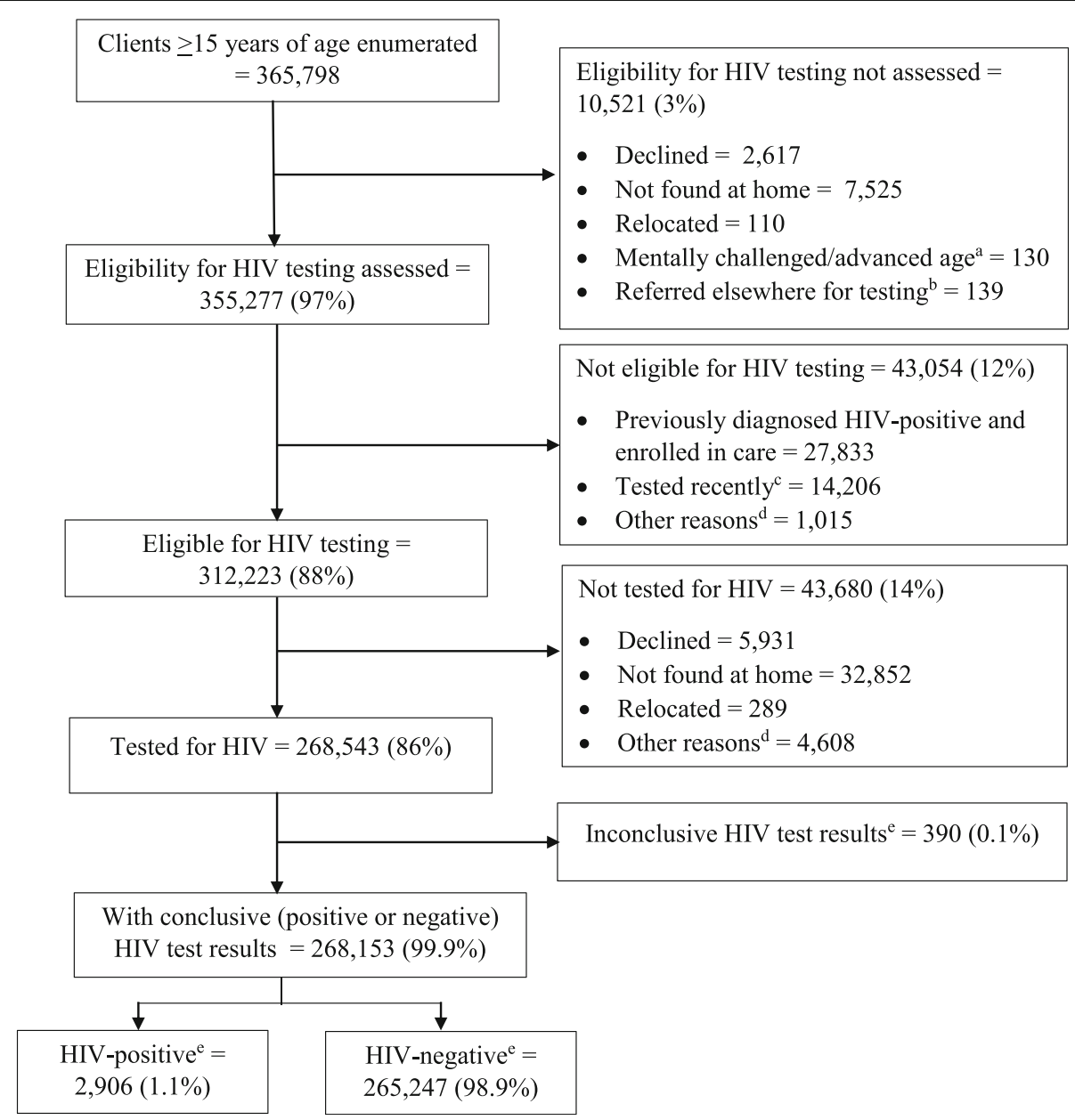

Fig. 1 Flowchart of clients receiving home-based HIV testing, Siaya County, May 2016-July 2017. 'Advanced age referred to elderly clients who were unable to comprehend HIV testing due to their diminished mental capacity related to old age. ${ }^{b} \mathrm{Clients} 15-24$ years of age in selected sublocations were referred to another program offering testing for young people. 'Self-reported tested recently within the prior 3 months. ${ }^{\mathrm{d} D e t a i l s}$ of other reasons not given. ${ }^{\mathrm{e}}$ An individual was considered HIV-negative (uninfected) if the Determine test result was negative (considered a conclusive negative result), HIV-positive (infected) if both the Determine and First Response serial tests results were positive (considered a conclusive positive result), and inconclusive if the Determine test was positive and First Response test was negative 
Table 1 Characteristics of clients aged $\geq 15$ years offered home-based HIV testing in Siaya County

\begin{tabular}{|c|c|c|c|c|c|c|}
\hline & $\begin{array}{l}\text { Enumerated, } \\
\mathrm{n}(\%)\end{array}$ & $\begin{array}{l}\text { Eligibility } \\
\text { assessed, n (\%) }\end{array}$ & $\begin{array}{l}\text { Eligible for HIV } \\
\text { testing, } n(\%)\end{array}$ & $\begin{array}{l}\text { Tested for HIV, } \\
\text { n (\%) }\end{array}$ & $\begin{array}{l}\text { With conclusive test } \\
\text { results, } \mathrm{n}\end{array}$ & $\begin{array}{l}\text { HIV-positive, } \\
\text { n (\%) }\end{array}$ \\
\hline Total clients & $365,798(100 \%)$ & $355,277(97 \%)$ & $312,223(88 \%)$ & $268,543(86 \%)$ & 268,153 & $2906(1.1 \%)^{a}$ \\
\hline \multicolumn{7}{|c|}{ Relationship to household head } \\
\hline Household head ${ }^{b}$ & $136,607(37 \%)$ & $132,622(37 \%)$ & $111,024(36 \%)$ & $94,506(35 \%)$ & 94,349 & $1432(1.5 \%)$ \\
\hline Spouse & 80,161 (22\%) & 78,756 (22\%) & $66,124(21 \%)$ & $60,660(23 \%)$ & 60,545 & $848(1.4 \%)$ \\
\hline Children $\geq 15$ years & $110,255(30 \%)$ & 105,999 (30\%) & 99,144 (32\%) & 80,781 (30\%) & 80,698 & $345(0.4 \%)$ \\
\hline Relatives \& non-relatives & $38,775(11 \%)$ & $37,900(11)$ & $35,931(11 \%)$ & $32,596(12 \%)$ & 32,561 & $281(0.9 \%)$ \\
\hline $\begin{array}{l}\text { Age (median, } \\
\text { interquartile range) }\end{array}$ & $30(20,47)$ & $30(20,47)$ & $28(19,46)$ & $28(19,47)$ & & \\
\hline \multicolumn{7}{|l|}{ Age group (years) } \\
\hline $15-19$ & 88,758 (24\%) & 85,813 (24\%) & 81,979 (26\%) & $69,651(26 \%)$ & 69,580 & $166(0.2 \%)$ \\
\hline $20-24$ & $52,952(14 \%)$ & $51,579(14 \%)$ & $47,722(15 \%)$ & $41,738(16 \%)$ & 41,682 & $442(1.1 \%)$ \\
\hline $25-35$ & $82,771(23 \%)$ & $80,349(23 \%)$ & $67,381(22 \%)$ & $57,238(21 \%)$ & 57,138 & $1096(1.9 \%)$ \\
\hline$>35$ & $141,317(39 \%)$ & $137,536(39 \%)$ & $115,141(37 \%)$ & $99,916(37 \%)$ & 99,753 & $1202(1.2 \%)$ \\
\hline \multicolumn{7}{|l|}{ Sex } \\
\hline Men & $162,628(44 \%)$ & $156,410(44 \%)$ & $141,011(45 \%)$ & $114,349(43 \%)$ & 114,187 & $1123(1.0 \%)$ \\
\hline Women & $203,170(56 \%)$ & $198,867(56 \%)$ & $171,212(55 \%)$ & $154,194(57 \%)$ & 153,966 & $1783(1.2 \%)$ \\
\hline \multicolumn{7}{|l|}{ Marital status ${ }^{c}$} \\
\hline Single & & & & $102,988(38 \%)$ & 102,887 & $442(0.4 \%)$ \\
\hline Married monogamous & & & & $131,034(49 \%)$ & 130,802 & $1844(1.4 \%)$ \\
\hline Married polygamous & & & & $6284(2 \%)$ & 6275 & $154(2.5 \%)$ \\
\hline Separated/divorced & & & & $1917(1 \%)$ & 1913 & $100(5.2 \%)$ \\
\hline Widow/widower & & & & $26,317(10 \%)$ & 26,273 & $363(1.4 \%)$ \\
\hline \multicolumn{7}{|l|}{ Time since last HIV test ${ }^{c}$} \\
\hline$<3$ months & & & & $2521(1 \%)$ & 2516 & $32(1.3 \%)$ \\
\hline 3-12 months & & & & $183,854(69 \%)$ & 183,606 & $1711(0.9 \%)$ \\
\hline$>12$ months & & & & 64,870 (24\%) & 64,761 & $951(1.5 \%)$ \\
\hline Never tested & & & & $17,298(6 \%)$ & 17,270 & $212(1.2 \%)$ \\
\hline
\end{tabular}

In addition to the new diagnoses of 2906, a total of 27,833 previously diagnosed HIV-positive clients were identified; the proportion of total HIV-positive clients was $8.7 \%$ among those whose eligibility was assessed

${ }^{\mathrm{b}}$ Among household heads, 81,599 (60\%) were men and 55,008 (40\%) women

'These variables were collected only for clients tested for HIV

Abbreviation: $n$, number

significant spatial autocorrelation of new HIV diagnoses. Nine significant sub-location clusters of higher new HIV diagnoses were identified (Fig. 2, Table 2) with cluster relative risk ranging from 1.56 to 2.64 , and radius ranging from 3.15 to $4.91 \mathrm{~km}$. Seven of the nine clusters were located centrally in the area around, and stretching eastward and westward of Ndere town; one cluster was in the area around Ndori town, where four major roads intersect; and another was located in the south, adjacent to Lake Victoria (Fig. 2). The sub-location cluster with the highest relative risk of 2.64 was located north-east of Ngiya town in a predominantly rural area. Significant clusters of lower new HIV diagnoses were located in the south-eastern part of the county (Fig. 2, Table 2), the area around and stretching southward of Yala town; the area south-east of Ngiya town; and the area adjacent to Lake Victoria, and stretching north, west and south-west of Asembo town. Major roads passed through areas with clusters of higher and lower new HIV diagnoses.

\section{Sub-location patterns of HIV testing uptake}

HIV testing uptake at sub-location level overlaid with clusters of new HIV diagnoses is shown in Fig. 3. The majority of sub-locations in clusters with higher new HIV diagnoses had high (> 87\%) HIV testing uptake, with exceptions observed in sub-locations located southeast of Luhano town; north, north-east, and east of Ngiya town; and west of Ndori town, which all had HIV testing uptake $<82 \%$. 


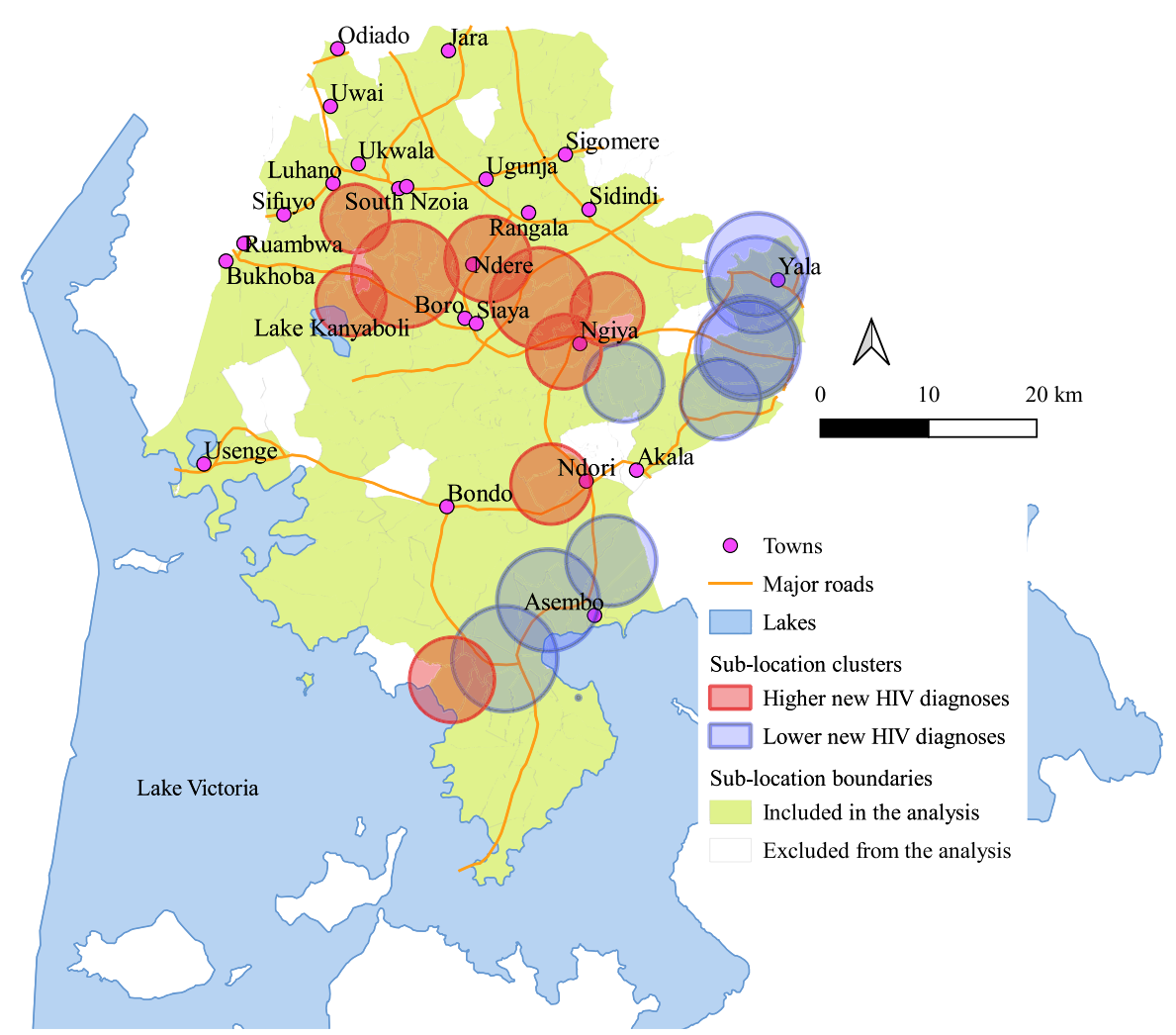

Fig. 2 Sub-location clusters of new HIV diagnoses from home-based HIV testing in Siaya County. Spatial clusters of new HIV diagnoses were detected using the Kulldorff's spatial scan statistic, implemented using SaTScan ${ }^{\text {TM }}$ version 9.6 (http://www.satscan.org). Spatial clusters were mapped and layered over ecological features using a standard Geographical Information System (GIS) program, Quantum GIS version 3.6 (http:// qgis.org). Shown in red circles are sub-location clusters of higher new HIV diagnoses with a relative risk of $>1.0$ at $p$ value $<0.05$, and in blue circles sub-location clusters of lower new HIV diagnoses with a relative risk of $<1.0$ at $p$ value $<0.05$. The boundary information for sub-locations in Siaya was obtained as shapefiles from DIVA-GIS (https://www.diva-gis.org/gdata)

Associations of new HIV diagnoses in the Bayesian model In unadjusted analysis, clients aged 20-24 years (uRR 4.44, 95\% CI 3.73-5.33), 25-35 years (uRR 8.03, 95\% CI 6.849.48) and $>35$ years ( $u R R ~ 5.05$, 95\% CI 4.3-5.96) were more likely diagnosed HIV-positive compared to those aged 15-19 years (Table 3). Men (uRR 0.85, 95\% CI 0.790.92) were less likely diagnosed HIV-positive compared to women. Compared to clients in monogamous marriage, clients in polygamous marriage (uRR 1.74, 95\% CI 1.472.04) or separated/divorced (uRR 3.71, 95\% CI 3.01-4.51) were more likely diagnosed HIV-positive; while those single (uRR 0.3, 95\% CI 0.27-0.34) were less likely diagnosed HIV-positive. Compared to those who reported had tested for HIV 3-12 months ago, those who had never tested (uRR 1.3, 95\% CI 1.12-1.5) and those who had tested > 12 months ago (uRR 1.58, 95\% CI 1.46-1.71) were more likely diagnosed HIV-positive.

The non-spatial and spatial random effect multivariable models used to explore factors associated with HIVpositive diagnosis are shown in Table 3. Of the four multivariable models explored, the convolution model that consisted of both a spatially structured and unstructured random effect model performed best with a deviation information criterion of $10,810.58$. In this model, there was no association between sex (men compared to women) and HIV-positive diagnosis. Clients aged 20-24 years (aRR 3.45, 95\% CI 2.85-4.20), 25-35 years (aRR $4.76,95 \%$ CI $3.92-5.81$ ) and $>35$ years (aRR 2.44, 95\% CI 1.99-3.00); clients in polygamous marriage (aRR 1.84, 95\% CI 1.55-2.16), or separated/divorced (aRR 3.36, 95\% CI 2.72-4.08); and clients never tested (aRR 2.35, 95\% CI 2.02-2.72) and those who had tested > 12 months ago (aRR 1.53, 95\% CI 1.41-1.66) were more likely to be diagnosed HIV-positive. The proportion of total HIV-positive clients in a sub-location (aRR 1.3, 95\% CI 1.07-1.60) was also positively associated with HIV diagnosis. Clients whose marital status was single (aRR 0.50, 95\% CI $0.44-$ 0.57 ) were less likely to be diagnosed HIV-positive.

Maps of the unstructured and structured estimated median value of the random effects for each sublocation, 
Table 2 Characteristics of clusters of new HIV diagnosesa in Siaya County

\begin{tabular}{|c|c|c|c|c|c|c|c|}
\hline $\begin{array}{l}\text { Number of sub- } \\
\text { locations in the } \\
\text { cluster }\end{array}$ & Names of sub-locations in the cluster & $\begin{array}{l}\text { Radius } \\
\text { (kilometers) }\end{array}$ & $\begin{array}{l}\text { Observed } \\
\text { cases }\end{array}$ & $\begin{array}{l}\text { Expected } \\
\text { cases }\end{array}$ & $\begin{array}{l}\text { Relative } \\
\text { risk }\end{array}$ & $\begin{array}{l}\text { Log likelihood } \\
\text { ratio }\end{array}$ & $P$ value \\
\hline \multicolumn{8}{|c|}{ Clusters with significant $(p$ value $<0.05$ ) higher new HIV diagnoses } \\
\hline 3 & Malunga West, Sirembe, Malunga East & 3.36 & 49 & 18.79 & 2.64 & 16.91 & $<0.001$ \\
\hline 2 & Gangu, Ojwando 'A' & 3.24 & 62 & 28.57 & 2.2 & 14.81 & $<0.001$ \\
\hline 7 & $\begin{array}{l}\text { Kochieng 'A', Kodiere, Ojwado 'B', Kochieng 'B', } \\
\text { Koyeyo, Komeny, Kalaka, Ojwando 'A' }\end{array}$ & 4.91 & 145 & 70.32 & 2.12 & 31.24 & $<0.001$ \\
\hline 5 & $\begin{array}{l}\text { Komolo, Hono, Kukumu_kombewa, Nyalgunga, } \\
\text { Koyeyo }\end{array}$ & 3.95 & 140 & 72.96 & 1.97 & 25.01 & $<0.001$ \\
\hline 4 & $\begin{array}{l}\text { Komenya Kowala, Kalkada Uradi, Komenya } \\
\text { Kalaka, Simur Kondiek }\end{array}$ & 3.15 & 72 & 38.93 & 1.87 & 11.4 & 0.002 \\
\hline 7 & $\begin{array}{l}\text { Ulafu, Umala, Nyalgunga, Nyamila, Olwa, Hono, } \\
\text { Karapul }\end{array}$ & 4.65 & 197 & 111.58 & 1.82 & 27.89 & $<0.001$ \\
\hline 4 & Mur_ngiya, Olwa, Masumbi, Umala & 3.43 & 91 & 57.76 & 1.59 & 8.32 & 0.026 \\
\hline 3 & Bar Chando, Abom, North Ramba & 3.69 & 97 & 62.91 & 1.56 & 8.12 & 0.032 \\
\hline 2 & Kagwa, Kokwiri & 3.92 & 81 & 47.93 & 1.71 & 9.62 & 0.008 \\
\hline \multicolumn{8}{|c|}{ Clusters with significant $(p$ value $<0.05$ ) lower new HIV diagnoses } \\
\hline 5 & Gombe, Onyinyore, Ramula, Kambare, Uranga & 3.69 & 68 & 115.55 & 0.58 & 11.9 & $<0.001$ \\
\hline 5 & $\begin{array}{l}\text { Omia Malo, Omia Diere, Memba, South Ramba, } \\
\text { Omia Mwalo }\end{array}$ & 4.14 & 81 & 150.33 & 0.53 & 20.11 & $<0.001$ \\
\hline 4 & Lihanda, Uranga, Marenyo, Ramula & 4.38 & 78 & 146.24 & 0.52 & 20.05 & $<0.001$ \\
\hline 6 & $\begin{array}{l}\text { Bar Sauri, Nyamninia, Anyiko_yala, Jina, Nyawara, } \\
\text { Nyandiwa_yala }\end{array}$ & 4.71 & 80 & 154.24 & 0.51 & 22.72 & $<0.001$ \\
\hline 5 & $\begin{array}{l}\text { Dienya East, Nguge, Dienya West, Ulamba, } \\
\text { Wagai West }\end{array}$ & 3.61 & 32 & 62.12 & 0.51 & 9.05 & 0.014 \\
\hline 7 & $\begin{array}{l}\text { Nyamninia, Bar Sauri, Jina, Nyandiwa_yala, } \\
\text { Anyiko_yala, Nyawara, Marenyo }\end{array}$ & 4.41 & 99 & 192.71 & 0.5 & 29.37 & $<0.001$ \\
\hline 5 & $\begin{array}{l}\text { Lihanda, Uranga, Marenyo, Ramula, Nyandiwa_ } \\
\text { yala }\end{array}$ & 4.78 & 86 & 180.17 & 0.46 & 32.17 & $<0.001$ \\
\hline 4 & Mahaya, Akom, Memba, Nyagoko & 4.68 & 56 & 119.77 & 0.46 & 21.92 & $<0.001$ \\
\hline 5 & Masala, Rachar, Akom, Kobong', Nyagoko & 4.85 & 63 & 164.62 & 0.37 & 42.97 & $<0.001$ \\
\hline 1 & Ochieng'a & 0 & 2 & 31.7 & 0.06 & 24.33 & $<0.001$ \\
\hline
\end{tabular}

${ }^{a}$ Sub-location clusters of new HIV diagnoses were mapped using SaTScan, which gradually scans a window cyclically across space, noting the number of observed and expected observations inside the window at each location, adjusting for the underlying spatial inhomogeneity of the background population

generated from the convolution Bayesian Poisson model, are shown in Fig. 4. The maps show the pattern of random effects, that further explain the distribution of new HIV diagnoses, over and above what is explained by the fixed effects (age group, sex, marital status, time since last HIV test and sub-location proportion of total HIVpositive clients). Figure 4 (a) shows the pattern of posterior median unstructured random effects, not taking into account spatial autocorrelation. When spatial autocorrelation was taken into account, as shown in Fig. 4 (b), the pattern of posterior median random effects changed, with more darker areas in the central region, demonstrating higher influence of spatially correlated random effects in this area.

Sub-location level exceedance probability of new HIV diagnoses is shown in Fig. 5. The darker colors show areas of high probabilities, while the lighter colors show areas of low probabilities.

\section{Discussion}

Our study uniquely demonstrates the use of geospatial analysis in a routine public health program to assess geospatial patterns of new HIV diagnoses, and identify geographic areas where HIV interventions could be targeted with finer granularity. Although the HIV epidemic in Siaya is generalized, our study found spatial variation in new HIV diagnoses, and identified sub-location clusters in which the number of new HIV diagnoses observed was 1.56 to 2.64 times higher than expected. We also identified sub-locations with higher exceedance probability of new HIV diagnoses, indicating areas where the probability of new HIV diagnoses are high. 


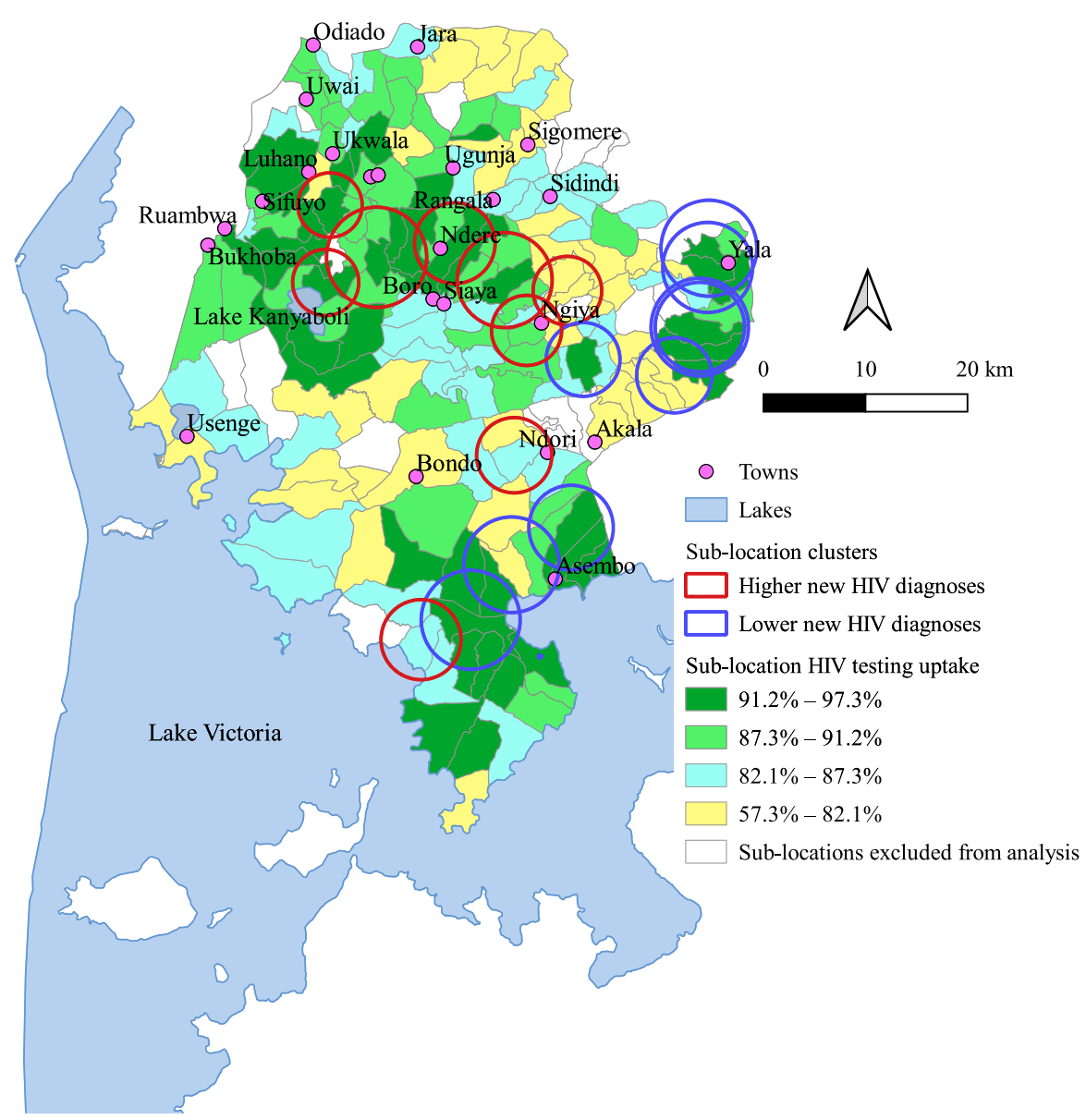

Fig. 3 Sub-location HIV testing uptake overlaid with clusters of new HIV diagnoses, Siaya County. A standard Geographical Information System (GIS) program, Quantum GIS version 3.6 (http://qgis.org) was used to map HIV testing uptake, and overlay sub-location clusters of new HIV diagnoses. The sub-location HIV testing uptake is in quantiles. The clusters of new HIV diagnoses were detected using the Kulldorff's spatial scan statistic, implemented using SaTScan ${ }^{\mathrm{TM}}$ version 9.6 (http://www.satscan.org). Shown in red circles are sub-location clusters of higher new HIV diagnoses with a relative risk of $>1.0$ at $p$ value $<0.05$, and in blue circles sub-location clusters of lower new HIV diagnoses with a relative risk of $<1.0$ at $p$ value $<0.05$. The boundary information for sub-locations in Siaya was obtained as shapefiles from

DIVA-GIS (https://www.diva-gis.org/gdata)

Geographic clusters of higher new HIV diagnoses may be attributed to having a high number of undiagnosed PLHIV, a high number of incident HIV infections, increased access to HIV testing, or a combination of these factors. It would, therefore, be beneficial to target intensified HIV prevention and testing interventions to these areas, as they may have relatively more undiagnosed PLHIV unreached by the program, and continued HIV transmission driven by high viral load levels among undiagnosed and newly diagnosed HIV-infected individuals.

Several studies have described ways to prioritize HIV interventions to specific geographic areas as a means to improve efficiency and cost-effectiveness; these include mapping the geographic distribution of ART coverage [38], and the distribution of sub-populations with higher
HIV-risk [11] or higher HIV prevalence [11, 18, 19]. Additionally, studies have described opportunities to utilize geospatial analysis and mapping to support targeting of HIV program interventions towards achievement of HIV epidemic control [20, 39]. To our knowledge, this study is the first to map fine $(\leq 5 \mathrm{~km}$ radius) clusters of higher HIV diagnoses using routine data from a home-based HIV testing program. A similar study done in Kenya used routine facility-level HIV testing data to identified facility clusters (at a radius of $\leq 50$ $\mathrm{km}$ ) of newly diagnosed HIV-positive persons across counties with differing HIV burden [21]. Other routinely available HIV testing data [e.g., provider-initiated testing and counseling data at health facilities, data from partner HIV testing services (index testing), antenatal clinic data, etc.] could be used in a similar manner. 
Table 3 Factors associated with new HIV diagnoses in non-spatial and spatial models, Siaya County

\begin{tabular}{|c|c|c|c|c|c|}
\hline & \multirow{2}{*}{$\begin{array}{l}\text { Unadjusted } \\
\text { relative risk } \\
\text { (uRR) }\end{array}$} & \multicolumn{4}{|c|}{ Adjusted relative risk (aRR) } \\
\hline & & Fixed effects only & $\begin{array}{l}\text { Spatially unstructured } \\
\text { model }\end{array}$ & $\begin{array}{l}\text { Spatially structured } \\
\text { model }\end{array}$ & $\begin{array}{l}\text { Convolution spatially } \\
\text { unstructured and } \\
\text { structured model }\end{array}$ \\
\hline & uRR $(95 \% \mathrm{Cl})$ & aRR $(95 \% \mathrm{Cl})$ & aRR $(95 \% \mathrm{Cl})$ & aRR $(95 \% \mathrm{Cl})$ & aRR $(95 \% \mathrm{Cl})$ \\
\hline \multicolumn{6}{|l|}{ Age groups (years) } \\
\hline $15-19$ & 1.00 (ref) & 1.00 (ref) & 1.00 (ref) & 1.00 (ref) & 1.00 (ref) \\
\hline $20-24$ & $4.44(3.73-5.33)$ & $3.55(2.94-4.31)$ & $3.46(2.86-4.2)$ & $3.45(2.85-4.19)$ & $3.45(2.85-4.2)$ \\
\hline $25-35$ & $8.03(6.84-9.48)$ & $4.78(3.94-5.83)$ & $4.78(3.93-5.82)$ & $4.76(3.92-5.81)$ & $4.76(3.92-5.81)$ \\
\hline$>35$ & $5.05(4.3-5.96)$ & $2.44(1.99-3)$ & $2.45(2-3.01)$ & $2.44(1.99-3)$ & $2.44(1.99-3)$ \\
\hline \multicolumn{6}{|l|}{ Sex } \\
\hline Women & 1.00 (ref) & 1.00 (ref) & 1.00 (ref) & 1.00 (ref) & 1.00 (ref) \\
\hline Men & $0.85(0.79-0.92)$ & $0.95(0.88-1.03)$ & $0.96(0.89-1.04)$ & $0.96(0.89-1.04)$ & $0.96(0.89-1.04)$ \\
\hline \multicolumn{6}{|l|}{ Marital status } \\
\hline Married monogamous & 1.00 (ref) & 1.00 (ref) & 1.00 (ref) & 1.00 (ref) & 1.00 (ref) \\
\hline Married polygamous & $1.74(1.47-2.04)$ & $1.86(1.57-2.19)$ & $1.84(1.55-2.17)$ & $1.84(1.55-2.17)$ & $1.84(1.55-2.16)$ \\
\hline Separated/divorced & $3.71(3.01-4.51)$ & $3.35(2.72-4.08)$ & $3.37(2.73-4.1)$ & $3.36(2.72-4.08)$ & $3.36(2.72-4.08)$ \\
\hline Single & $0.3(0.27-0.34)$ & $0.49(0.42-0.55)$ & $0.5(0.44-0.57)$ & $0.5(0.44-0.57)$ & $0.5(0.44-0.57)$ \\
\hline Widow/widower & $0.98(0.87-1.1)$ & $1.13(0.99-1.28)$ & $1.1(0.97-1.24)$ & $1.1(0.97-1.24)$ & $1.1(0.97-1.24)$ \\
\hline \multicolumn{6}{|l|}{ Time since last HIV test } \\
\hline$<3$ months & $1.36(0.94-1.9)$ & $1.31(0.9-1.81)$ & $1.31(0.9-1.83)$ & $1.33(0.91-1.85)$ & $1.33(0.91-1.85)$ \\
\hline 3-12 months & 1.00 (ref) & 1.00 (ref) & 1.00 (ref) & 1.00 (ref) & 1.00 (ref) \\
\hline$>12$ months & $1.58(1.46-1.71)$ & $1.51(1.39-1.63)$ & $1.54(1.41-1.67)$ & $1.53(1.41-1.66)$ & $1.53(1.41-1.66)$ \\
\hline Never tested & $1.3(1.12-1.5)$ & $2.37(2.04-2.74)$ & $2.35(2.02-2.73)$ & $2.35(2.01-2.72)$ & $2.35(2.02-2.72)$ \\
\hline $\begin{array}{l}\text { Sub-location proportion of } \\
\text { total HIV-positive clients }{ }^{\mathrm{a}}\end{array}$ & $1.61(1.43-1.8)$ & $1.5(1.34-1.68)$ & $1.49(1.21-1.82)$ & $1.26(1.04-1.53)$ & $1.3(1.07-1.6)$ \\
\hline \multicolumn{6}{|l|}{ Random effects } \\
\hline Spatially unstructured precis & & & $6.01(4.37-8.27)$ & & 17.39 (9.01-36.14) \\
\hline Spatially structured precision & & & & $2.44(1.67-3.59)$ & $4.97(2.5-9.24)$ \\
\hline \multicolumn{6}{|l|}{ Model comparison } \\
\hline Effective number of parame & & 13 & 125.12 & 109.09 & 113.8 \\
\hline Deviation information criteri & & $11,153.63$ & $10,816.12$ & $10,811.64$ & $10,810.58$ \\
\hline
\end{tabular}

${ }^{a}$ The proportion of total HIV-positive clients was defined as the sum of the total new HIV-positive and previously identified HIV-infected clients among those whose eligibility for HIV testing was assessed

Abbreviations: uRR, unadjusted relative risk; aRR, adjusted relative risk; $\mathrm{Cl}$, credible interval

Our study further identified sub-locations with both higher new HIV diagnoses and low testing uptake. A study in Zimbabwe demonstrated the use of geospatial analysis to target areas for increased uptake of HIV services, including those with high HIV prevalence [40]. Our findings, therefore, add to the literature base describing the utility of geospatial analysis in identifying areas with potentially high HIV-positive yield that could be efficiently targeted to increase HIV testing uptake.

In Siaya, clusters of higher new HIV diagnoses were found in areas around specific towns, around major roads, near a major road intersection and adjacent to a beach. Although geospatial clustering of new HIV diagnoses has not yet been described in the literature, other studies have described the clustering of higher HIV prevalence [10, 13] and incidence [12] around similar ecological factors. The clustering around ecological features observed in our study suggests that populationlevel factors related to the ecological features, including socioeconomic, mobility and geographic factors, may influence the clustering of new HIV diagnoses. Surprisingly, however, the sub-location cluster with the highest relative risk was in a predominantly rural area with no prominent ecological features. Furthermore, several sublocations around towns and major roads had clusters of lower new HIV diagnoses, suggesting that other unidentified factors unrelated to ecological factors, additionally influence the distribution of new HIV diagnoses. 


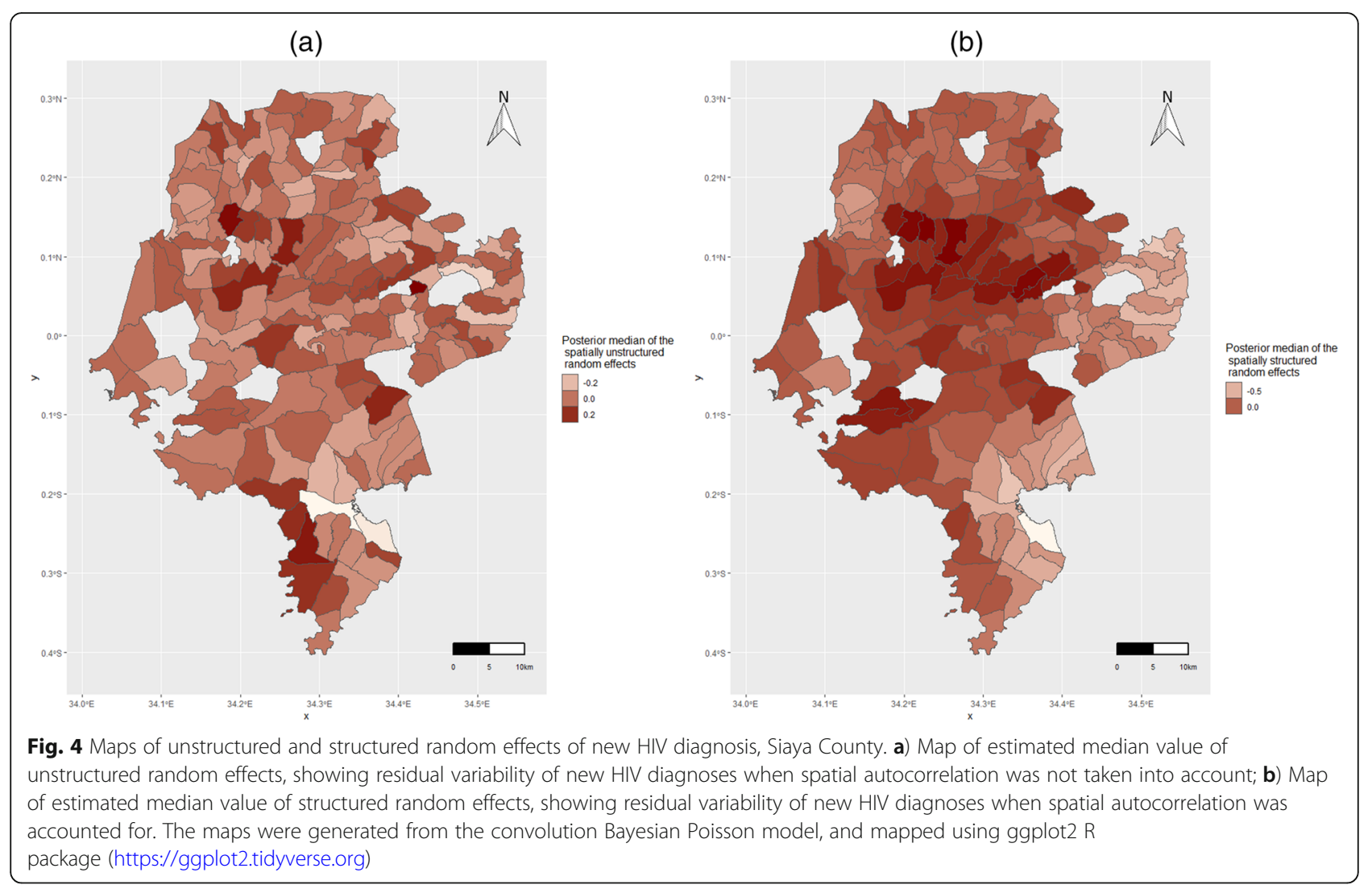

A Bayesian model was used to enable assessment of individual and spatial-level associations of new HIV diagnoses in a spatially-integrated framework. Spatial effects influenced the distribution of new HIV diagnoses, influencing the degree of association of individual-level factors, and further influencing the pattern of random effects (the distribution of new HIV diagnoses not explained by factors in the Bayesian model). In the spatial Bayesian model, we found that clients in polygamous marriage and those separated/divorced were more likely diagnosed HIV-positive, likely due to their higher risk of HIV infection as shown in other studies [41-45]. Polygamous marriages permit concurrent sexual partnerships [46] and correlates with low rates of condom use [47]. Separated/divorced women have been shown to have a higher risk of HIV [48], as these women may seek new sexual relationships that put them at higher risk of HIV, or HIV infection may have contributed to the divorce/ separation [49]. Although several studies have documented a correlation between widowhood and higher HIV infection [44, 45, 50], a significant association between widowed individuals and HIV-positive diagnosis was not observed in this study. Similar to findings observed in facility-based testing [51], individuals never tested for HIV, and those tested > 12 months prior, were more likely to be diagnosed HIV-positive. The association between increasing age and higher likelihood of
HIV diagnosis found in this study is consistent with higher HIV prevalence observed in older age groups [52-54]. Although other studies have shown that men have lower HIV prevalence compared to women, our spatial model did not find a significant association between HIV-positive diagnosis and sex. The association observed between higher proportion of total HIVpositive clients in a sub-location and higher new HIV diagnoses suggests these areas likely have a relatively high number of undiagnosed PLHIV and ongoing local HIV transmission. Random effects or additional factors beyond those included in the Bayesian model, influenced the distribution of new HIV diagnoses (Fig. 4). This points out to the importance of other factors, likely other individual or population-level factors (including geographic, economic or social), that influenced the pattern of new HIV diagnoses.

Home-based HIV testing conducted in Siaya between May 2016 and July 2017 achieved high (86\%) HIV testing uptake among eligible individuals; and was comparable to the testing uptake (64 to 99\%) reported in other home-based testing programs in sub-Saharan Africa [55]. The proportion of new HIV diagnoses was low (1.1\% HIV-positive yield), slightly lower than that observed in outpatient HIV testing services (1.3\% yield) in this setting [51]. The low yield observed is likely due to a diminishing number of undiagnosed PLHIV in the 


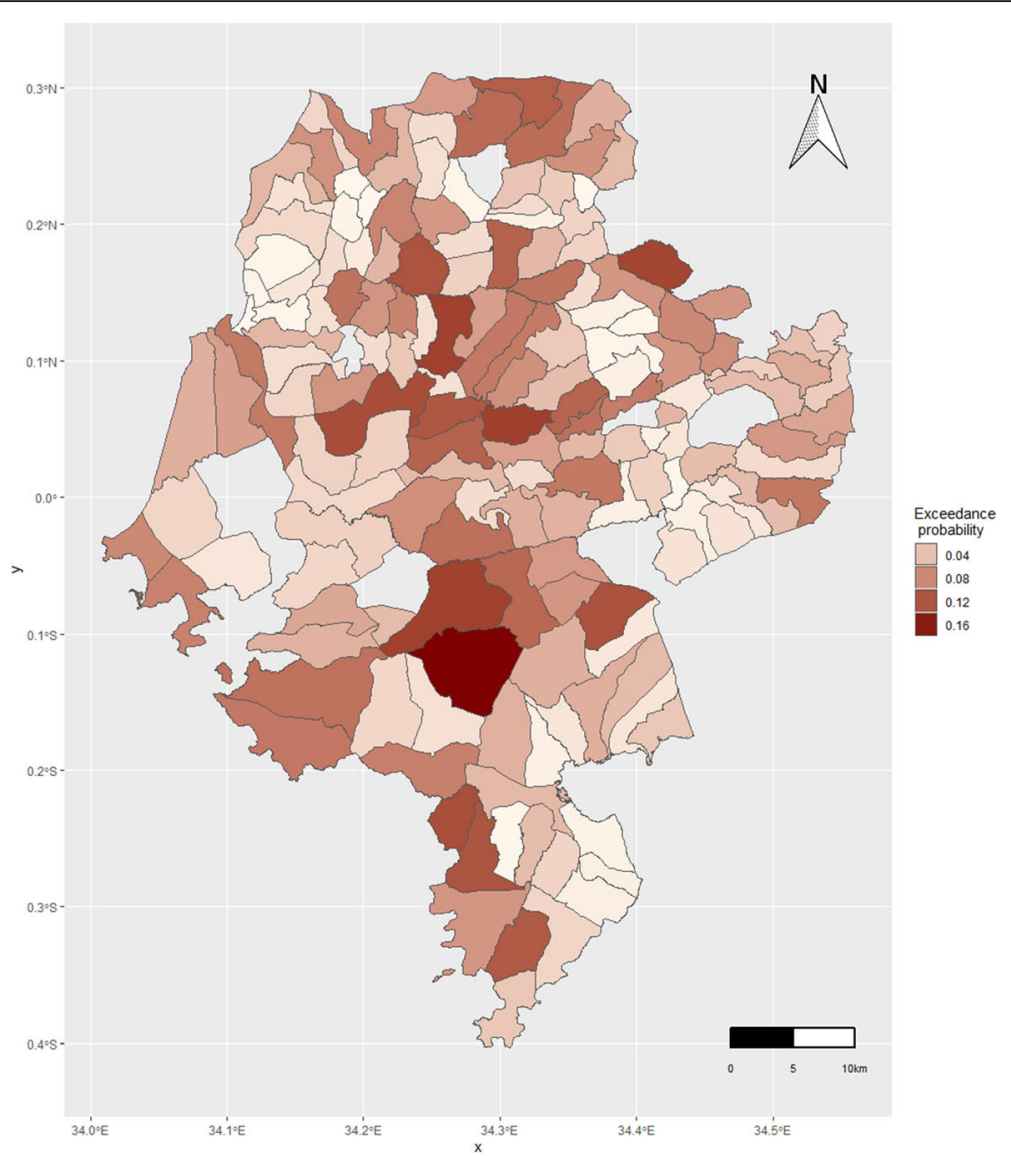

Fig. 5 Map of exceedance probability of new HIV diagnosis, Siaya County. The posterior probability of the sub-location's relative risk to exceed a threshold was calculated using the Bayesian approach. For our analysis, a threshold of 1.25 was used. The darker colors show areas of high probabilities, while the lighter colors show areas of low probabilities. The map was created using ggplot2 R package (https://ggplot2.tidyverse.org)

general population, and further highlights the importance of granular spatial analysis to better target HIV testing programs.

We compared the number of individuals aged $>15$ years enumerated for home-based testing in the 161 sub-locations included in our analysis (365,798 clients), with 2016/2017 corresponding projected population (435,727 individuals). The projected population was derived using 2009 [56] and 2019 [57] Kenya population census reports. From this, we estimate that majority ( $84 \%$ ) of residents aged $\geq 15$ years in the 161 sublocations included in our analysis were enumerated for home-based testing.

Our study had some limitations. First, our results do not represent the whole of Siaya County, as data for 18 sub-locations were excluded; our study did, however, include the majority (90\%) of sub-locations in the county. Second, we encountered several limitations owing to the use of routinely collected data for home-based testing, namely: HIV testing procedures were those set for the routine home-based testing program; during enumeration, household residents who reported they would be away for more than one-month following enumeration were excluded, which might have reduced representation of adolescents in boarding schools/colleges; data were not available to verify the number of households in each sub-location enumerated; and variables included in our analysis of factors associated with new HIV diagnoses were limited to those routinely collected, and therefore we were not able to explore other variables likely associated with new HIV diagnoses. Third, per Kenya Ministry of Health guidelines, the assessment of HIV testing eligibility relied on self-reported previous HIV testing, which can be unreliable [58].

Finally, despite literature showing utility of geospatial analysis in informing geographic-targeting of HIV interventions [20,21,39], geospatial analysis is not routinely used in public health programs. Our study demonstrates the feasibility of using routine HIV testing data for geospatial analysis, to identify granular $(\leq 5 \mathrm{~km})$ geographic 
areas to target HIV testing and other interventions. We recommend that countries and programs should integrate geospatial analysis into routine public health program data analysis and use, to inform targeting of interventions to more granular geographic units for maximal epidemiologic impact and efficient resource allocation.

\section{Conclusions}

Our study uniquely demonstrates the use of geospatial analysis in a routine public health program, to identify geographic areas with higher new HIV diagnoses where HIV interventions could be targeted with finer granularity. Additionally, we demonstrate sub-populations with higher HIV-positive yield (i.e., older age groups, those in polygamous marriage or separated divorced, and those never tested for HIV, or tested HIV-negative > 12 months prior), that would benefit from continued targeted HIV testing and prevention interventions. As countries make progress towards HIV epidemic control, integrating geospatial analysis into routine public health programs would help focus interventions to more granular geographic units for maximal epidemiologic impact and efficient resource allocation.

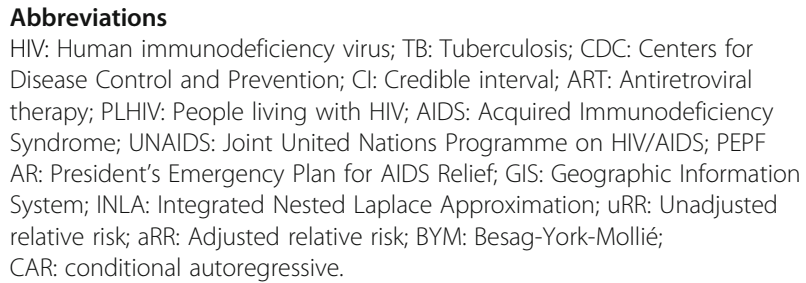
Disease Control and Prevention; Cl: Credible interval; ART: Antiretroviral therapy; PLHIV: People living with HIV; AIDS: Acquired Immunodeficiency Syndrome; UNAIDS: Joint United Nations Programme on HIV/AIDS; PEPF AR: President's Emergency Plan for AIDS Relief; GIS: Geographic Information System; INLA: Integrated Nested Laplace Approximation; URR: Unadjusted relative risk; aRR: Adjusted relative risk; BYM: Besag-York-Mollié;

CAR: conditional autoregressive.

\section{Supplementary Information}

The online version contains supplementary material available at https://doi. org/10.1186/s12889-021-11890-7.

Additional file 1.

\section{Acknowledgements}

The authors would like to thank the staff who implemented home-based HIV testing in Siaya (community mobilizers, enumerators, HIV testing counselors, data management staff and home-based testing coordinators), without whom this study would not have been possible. The authors would also like to thank the Kenya Ministry of Health and the Siaya County Department of Health for the support they provide to HIV testing services.

\section{Disclaimer}

The findings and conclusions in this report are those of the authors and do not necessarily represent the official position of the funding agencies.

\section{Authors' contributions}

Conceptualization: HM BG PM EZ. Data curation: HM PM JN RO1 WO RO2. Data analysis: PM TA JN HM. Writing original manuscript draft: HM. Writing, reviewing and editing manuscript: HM BG TA PM JN RO1 WO RO2 SO KA KO BA RJ FM EZ. All authors have read and approved the final manuscript.

\section{Funding}

This study used routinely collected data from home-based HIV testing supported by the United States President's Emergency Plan for AIDS Relief (PEPF
AR) through the United States Centers for Disease Control and Prevention, under the terms of cooperative agreement 1NU2GGH001963 to the Impact Research and Development Organization. Staff from Impact Research and Development Organization and the United States Centers for Disease Control and Prevention participated in the analysis, results interpretation, and manuscript writing.

\section{Availability of data and materials}

The datasets used and/or analyzed during this study are available from the corresponding author upon reasonable request.

\section{Declarations}

Ethics approval and consent to participate

The Institutional Review Board of Maseno University, Maseno, Kenya, approved the protocol to conduct this analysis. The protocol was also reviewed in accordance with the United States Centers for Disease Control and Prevention, Atlanta, Georgia, (CDC) human research protection procedures and was determined to be research, but CDC staff did not interact with or have access to identifiable data or specimens for research purposes. Informed consent was waived in line with the criteria outlined in 45CFR 46.116

\section{Consent for publication}

Not applicable.

\section{Competing interests}

The authors declare that they have no competing interests.

\section{Author details}

${ }^{1}$ Division of Global HIV \& TB, United States Centers for Disease Control and Prevention, 00621 Nairobi, Kenya. ${ }^{2}$ School of Public Health, Maseno University, Kisumu, Kenya. ${ }^{3}$ Impact Research and Development Organization, Kisumu, Kenya. ${ }^{4}$ Siaya County Department of Health, Siaya, Kenya. ${ }^{5}$ United States Centers for Disease Control and Prevention, Guatemala, Guatemala.

Received: 6 May 2020 Accepted: 30 September 2021

Published online: 23 October 2021

\section{References}

1. Joint United Nations Programme on HIV/AIDS. UNAIDS Data 2018. Geneva: Joint United Nations Programme on HIV/AIDS; 2019. Available from: https:// www.unaids.org/sites/default/files/media_asset/unaids-data-2018_en.pdf. Accessed 15 Nov 2019

2. US President's Emergency Plan for AIDS Relief. Strategy for Accelerating HIV/AIDS Epidemic Control (2017-2020). Washington DC: US President's Emergency Plan for AIDS Relief; 2017. Available from: https://www.state.gov/ wp-content/uploads/2019/08/PEPFAR-Strategy-for-Accelerating-HIVAIDSEpidemic-Control-2017-2020.pdf. Accessed 26 March 2019

3. Cohen MS, Chen YQ, McCauley M, Gamble T, Hosseinipour M, Kumarasamy $\mathrm{N}$, et al. Prevention of HIV-1 infection with early antiretroviral therapy. N Engl J Med. 2011;365(6):493-505. https://doi.org/10.1056/NEJMoa1105243.

4. Cohen MS, Chen YQ, McCauley M, Gamble T, Hosseinipour M, Kumarasamy $\mathrm{N}$, et al. Antiretroviral therapy for the prevention of HIV-1 transmission. N Engl J Med. 2016:375(9):830-9. https://doi.org/10.1056/NEJMoa1600693.

5. The INSIGHT START Study Group. Initiation of antiretroviral therapy in early asymptomatic HIV infection. N Engl J Med. 2015;373(9):795-807. https://doi. org/10.1056/NEJMoa1506816.

6. Joint United Nations Programme on HIV/AIDS. 90-90-90: An ambitious treatment target to help end the AIDS epidemic. Geneva: Joint United Nations Programme on HIV/AIDS; 2014. Available from: https://www.unaids. org/sites/default/files/media_asset/90-90-90_en.pdf. Accessed 15 Nov 2019

7. Kenya National AIDS Control Council. Kenya HIV Estimates Report. Nairobi: Kenya Ministry of Health; 2018. Available from: https://nacc.or.ke/wpcontent/uploads/2018/11/HIV-estimates-report-Kenya-20182.pdf. Accessed 6 March 2019

8. Tanser F, Bärnighausen T, Cooke G, Newell M. Localized spatial clustering of HIV infections in a widely disseminated rural south African epidemic. Int J Epidemiol. 2009;38(4):1008-16. https://doi.org/10.1093/ije/dyp148.

9. Zulu L, Kalipeni E, Johannes E. Analyzing spatial clustering and the spatiotemporal nature and trends of HIV/AIDS prevalence using GIS: the 
case of Malawi, 1994-2010. BMC Infect Dis. 2014;14(1):285. https://doi.org/1 0.1186/1471-2334-14-285.

10. Waruru A, Achia T, Tobias J, Ng'ang'a J, Mwangi M, Wamicwe J, et al. Finding Hidden HIV Clusters to Support Geographic-Oriented HIV Interventions in Kenya. J Acquir Immune Defic Syndr. 2018:78(2):144.

11. Cuadros D, Awad S, Abu-Raddad L. Mapping HIV clustering: a strategy for identifying populations at high risk of HIV infection in sub-Saharan Africa. Int J Health Geogr. 2013;12(1):28. https://doi.org/10.1186/1476-072X-12-28.

12. Tanser F, Bärnighausen T, Dobra A, Sartorius B. Identifying 'corridors of HIV transmission' in a severely affected rural south African population: a case for a shift toward targeted prevention strategies. Int J Epidemiol. 2017;47(2): 537-49. https://doi.org/10.1093/ije/dyx257.

13. Cuadros D, Abu L. Spatial variability in HIV prevalence declines in several countries in sub-Saharan Africa. Health Place. 2014;28:45-9. https://doi.org/1 0.1016/j.healthplace.2014.03.007.

14. Waruru A, Achia T, Muttai H, Zielinski-Gutierrez E, Ochanda B, Katana A, et al. Spatial-temporal trend for mother-to-child transmission of HIV up to infancy and during pre-option B+ in western Kenya, 2007-13. PeerJ. 2018;6: e4427. https://doi.org/10.7717/peerj.4427.

15. Yao J, Agadjanian V, Murray A. Spatial and social inequities in HIV testing utilization in the context of rapid scale-up of HIV/AIDS services in rural Mozambique. Health Place. 2014;28:133-41. https://doi.org/10.1016/j.hea Ithplace.2014.04.007.

16. Bassett I, Regan S, Mbonambi H, Blossom J, Bogan S, Bearnot B, et al. Finding HIV in hard to reach populations: mobile HIV testing and geospatial mapping in Umlazi township, Durban, South Africa. AIDS Behav. 2015;19(10): 1888-95. https://doi.org/10.1007/s10461-015-1012-3.

17. Goswami N, Hecker E, Vickery C, Ahearn M, Cox G, Holland D, et al. Geographic information system-based screening for TB, HIV, and syphilis (GIS-THIS): a cross-sectional study. PLoS One. 2012;7(10):e46029. https://doi. org/10.1371/journal.pone.0046029.

18. Wand H, Ramjee G. Targeting the hotspots: investigating spatial and demographic variations in HIV infection in small communities in South Africa. J Int AIDS Soc. 2010;13(1):41. https://doi.org/10.1186/1758-2652-13-41.

19. González R, Augusto O, Munguambe K, Pierrat C, Pedro E, Sacoor C, et al. HIV incidence and spatial clustering in a rural area of southern Mozambique. PLoS One. 2015;10(7):e0132053. https://doi.org/10.1371/journa I.pone.0132053.

20. Anderson S, Cherutich P, Kilonzo N, Cremin I, Fecht D, Kimanga D, et al. Maximising the effect of combination HIV prevention through prioritisation of the people and places in greatest need: a modelling study. Lancet. 2014;384(9939):249-56. https://doi.org/10.1016/S0140-673 6(14)61053-9.

21. Waruru A, Wamicwe J, Mwangi J, Achia T, Zielinski-Gutierrez E, Ng'ang'a L, et al. Where are the newly diagnosed HIV positives in Kenya? Time to consider geo-spatially guided targeting at a finer scale to reach the "first 90". Front Public Health. 2021;9:392. https://doi.org/10.3389/fpubh.2021.503 555.

22. National AIDS and STI Control Programme, Ministry of Health, Kenya. Guidelines for HIV Testing Services in Kenya. Nairobi: NASCOP; 2015. Available from: https:/www.fast-trackcities.org/sites/default/files/Kenya\%2 OHIV\%20Testing\%20Services\%20Guidelines\%20\%282015\%29.pdf. Accessed 11 Oct 2021

23. Abbot. Alere Determine ${ }^{T M}$ HIV-1/2. Chicago, Illinois: Abbot; 2019. Available from: https://www.globalpointofcare.abbott/en/product-details/determinehiv-1-2.html. Accessed 11 Oct 2021

24. Premier Medical Corporation Limited. First Response ${ }^{\oplus} \mathrm{HIV}$ 1-2-0 Human Immunodeficiency Virus Rapid Test Strip. Daman: Premier Medical Corporation Limited. Available from: http://premiermedcorp.com/wpcontent/uploads/2017/09/105FRS50-1.pdf. Accessed 2 Oct 2020

25. Anselin L, Ibnu S, Youngihn K. GeoDa: An Introduction to Spatial Data Analysis. 2016 Available from: https://geodacenter.github.io/. Accessed 3 Oct 2020.

26. Anselin L, Syabri I, Kho Y. GeoDa: an introduction to spatial data analysis. In: Handbook of applied spatial analysis: Springer; 2010. p. 73-89. https://doi. org/10.1007/978-3-642-03647-7_5.

27. Martin K, Neville N. Spatial disease clusters: detection and inference. Stat Med. 1995;14(8):799-810. https://doi.org/10.1002/sim.4780140809.

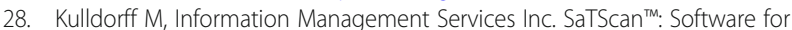
the spatial and space-time scan statistics. New York City: Department of
Health and Mental Hygiene; 2009. updated 19 October 2019. Available from: http://www.satscan.org/. Accessed 3 Oct 2020

29. Martin Kulldorff and Information Management Services Inc. SaTScanTM User Guide for version 9.6 2018. Available from: https:/www.satscan.org/cgi-bin/ satscan/register.pl/SaTScan_Users_Guide.pdf?todo=process_userguide_ download. Accessed 7 Oct 2020.

30. QGIS Development Team. QGIS Geographic Information System. Beaverton, Oregon, United States: Open Source Geospatial Foundation Project; 2021. Available from: http://qgis.org. Accessed 11 Oct 2021.

31. Rue H, Martino S, Chopin N. Approximate Bayesian inference for latent Gaussian models by using integrated nested Laplace approximations. J R Stat Soc Series B Stat Methodol. 2009;71(2):319-92.

32. Besag J, York J, Mollié A. Bayesian image restoration, with two applications in spatial statistics. Ann Inst Stat Math. 1991;43(1):1-20. https://doi.org/10.1 007/BF00116466.

33. Blangiardo M, Cameletti M, Baio G, Rue H. Spatial and spatio-temporal models with R-INLA. Spat Spatiotemporal Epidemiol. 2013;4:33-49. https:// doi.org/10.1016/j.sste.2012.12.001.

34. Annie M. Bayesian mapping of disease; 1996. p. 359-79.

35. Wickham H. ggplot2-Elegant Graphics for Data Analysis. New York: Springer International Publishing; 2016.

36. Nicky B, Sylvia R, Andrew T. A comparison of Bayesian spatial models for disease mapping. Stat Methods Med Res. 2005;14(1):35-59. https://doi.org/1 0.1191/0962280205sm3880a.

37. Md MH, Lawson Andrew B. Cluster detection diagnostics for small area health data: with reference to evaluation of local likelihood models. Stat Med. 2006;25(5):771-86. https://doi.org/10.1002/sim.2401.

38. Cooke G, Tanser F, Bärnighausen T, Newell M. Population uptake of antiretroviral treatment through primary care in rural South Africa. BMC Public Health. 2010;10(1):585. https://doi.org/10.1186/1471-2458-10-585.

39. Lilian R, Grobbelaar C, Hurter T, McIntyre J, Struthers H, Peters R. Application opportunities of geographic information systems analysis to support achievement of the UNAIDS 90-90-90 targets in South Africa. S Afr Med J. 2017;107(12):1065-71. https://doi.org/10.7196/SAMJ.2017.v107i12.12666.

40. Schaefer R, Gregson S, Takaruza A, Rhead R, Masoka T, Schur N, et al. Spatial patterns of HIV prevalence and service use in East Zimbabwe: implications for future targeting of interventions. J Int AIDS Soc. 2017;20(1):21409. https://doi.org/10.7448//AS.20.1.21409.

41. Adeokun LA, Nalwadda RM. Serial marriages and AIDS in Masaka District. Health Transit Rev. 1997;7:49-66.

42. Bove R, Valeggia C. Polygyny and women's health in sub-Saharan Africa. Soc Sci Med. 2009;68(1):21-9. https://doi.org/10.1016/j.socscimed.2008.09.045.

43. Kimanga DO, Ogola S, Umuro M. Prevalence and incidence of HIV infection, trends, and risk factors among persons aged 15-64 years in Kenya: results from a nationally representative study. J Acquir Immune Defic Syndr. 2014; 66(Suppl 1):S13-26. https://doi.org/10.1097/QAl.0000000000000124.

44. Tenkorang EY. Marriage, widowhood, divorce and HIV risks among women in sub-Saharan Africa. Int Health. 2014;6(1):46-53. https://doi.org/10.1093/ inthealth/ihu003.

45. Oluoch T, Mohammed I, Bunnell R, Kaiser R, Kim AA, Gichangi A, et al. Correlates of HIV infection among sexually active adults in Kenya: a national population-based survey. Open AIDS J. 2011;5(1):125-34. https://doi.org/1 $0.2174 / 1874613601105010125$.

46. Morris M, Kretzschmar M. Concurrent partnerships and the spread of HIV. AIDS. 1997;11(5):641-8. https://doi.org/10.1097/00002030-199705000-00012.

47. Tawfik L, Watkins SC. Sex in Geneva, sex in Lilongwe, and sex in Balaka. Soc Sci Med. 2007;64(5):1090-101. https://doi.org/10.1016/j.socscimed.2006.10. 002.

48. Boileau C, Clark S, Bignami-Van AS, Poulin M, Reniers G, Watkins SC, et al. Sexual and marital trajectories and HIV infection among ever-married women in rural Malawi. Sex Transm Infect. 2009;85(Suppl 1):i27-33. https:// doi.org/10.1136/sti.2008.033969.

49. Porter L, Hao L, Bishai D, Serwadda D, Wawer MJ, Lutalo T, et al. HIV status and union dissolution in sub-Saharan Africa: the case of Rakai, Uganda. Demography. 2004;41(3):465-82. https://doi.org/10.1353/dem.2004.0025.

50. Amornkul PN, Vandenhoudt H, Nasokho P, Odhiambo F, Mwaengo D, Hightower A, et al. HIV prevalence and associated risk factors among individuals aged 13-34 years in rural Western Kenya. PLoS One. 2009:4(7): e6470. https://doi.org/10.1371/journal.pone.0006470.

51. Joseph R, Musingila P, Miruka F, Wanjohi S, Dande C, Musee P, et al. Expanded eligibility for HIV testing increases HIV diagnoses-a cross- 
sectional study in seven health facilities in western Kenya. PLoS One. 2019; 14(12):e0225877. https://doi.org/10.1371/journal.pone.0225877.

52. National AIDS STI Control Programme Ministry of Health Kenya. Kenya AIDS indicator survey 2012. Nairobi: Ministry of Health Nairobi, Kenya; 2013. Available from: https:/nacc.or.ke/wp-content/uploads/2015/10/KAls-2012. pdf

53. Tanzania Commission for AIDS (TACAIDS), Zanzibar AIDS Commission (ZAC) Tanzania HIV Impact Survey (THIS) 2016-2017: Final Report. Dar es Salaam, Tanzania: TACAIDS and ZAC; December 2018. Available from: https://phia.ica p.columbia.edu/wp-content/uploads/2020/02/FINAL_THIS-2016-2017_FinalReport_06.21.19_for-web_TS.pdf. Accessed 11 Oct 2021.

54. Ministry of Health, Uganda. Uganda Population-based HIV Impact Assessment (UPHIA) 2016-2017: Final Report. Kampala: Uganda Ministry of Health; July, 2019. Available from: https://phia.icap.columbia.edu/ugandaphia-final-report/. Accessed 11 Oct 2021.

55. Sabapathy K, Van den Bergh R, Fidler S, Hayes R, Ford N. Uptake of homebased voluntary HIV testing in sub-Saharan Africa: a systematic review and meta-analysis. PLoS Med. 2012;9(12):e1001351. https://doi.org/10.1371/ journal.pmed.1001351.

56. Kenya National Bureau of Statistics. Kenya Population and Housing Census. Nairobi: Kenya National Bureau of Statistics; 2009. Available from: https:// www.knbs.or.ke/?page id=3142. Accessed 11 Oct 2020

57. Kenya National Bureau of Statistics. Kenya Population and Housing Census. Nairobi: Kenya National Bureau of Statistics; 2019. Available from: https:/ www.knbs.or.ke/?wpdmpro=2019-kenya-population-and-housing-censusvolume-i-population-by-county-and-sub-county. Accessed 22 April 2020

58. Kim A, Mukui I, Young P, Mirjahangir J, Mwanyumba S, Wamicwe J, et al. Undisclosed HIV infection and antiretroviral therapy use in the Kenya AIDS indicator survey 2012: relevance to national targets for HIV diagnosis and treatment. AIDS. 2016;30(17):2685-95. https://doi.org/10.1097/QAD. 0000000000001227.

\section{Publisher's Note}

Springer Nature remains neutral with regard to jurisdictional claims in published maps and institutional affiliations.

Ready to submit your research? Choose BMC and benefit from:

- fast, convenient online submission

- thorough peer review by experienced researchers in your field

- rapid publication on acceptance

- support for research data, including large and complex data types

- gold Open Access which fosters wider collaboration and increased citations

- maximum visibility for your research: over $100 \mathrm{M}$ website views per year

At $\mathrm{BMC}$, research is always in progress.

Learn more biomedcentral.com/submissions 